\title{
Diagnostic accuracy of insulin-like growth factor-1 for screening growth hormone deficiency: a prospective, single-center, diagnostic accuracy study
}

Hideyuki Iwayama ( $D$ iwahide1976@gmail.com )

Aichi Medical University

Sachiko Kitagawa

Daiyūkaidaiichi Hospital

Jyun Sada

Aichi Medical University

Ryosuke Miyamoto

Aichi Medical University

Tomohito Hayakawa

Aichi Medical University

Yoshiyuki Kuroyanagi

Aichi Medical University

Taichiro Muto

Aichi Medical University

Hirokazu Kurahashi

Aichi Medical University

Wataru Ohashi

Aichi Medical University

Junko Takagi

Aichi Medical University

Akihisa Okumura

Aichi Medical University

\section{Research Article}

Keywords: GHD, growth hormone (GH), MRI, electrochemiluminescence immunoassay, NPV

Posted Date: May 27th, 2021

DOI: https://doi.org/10.21203/rs.3.rs-547842/v1 
License: (c) (i) This work is licensed under a Creative Commons Attribution 4.0 International License. Read Full License

Version of Record: A version of this preprint was published at Scientific Reports on August 9th, 2021. See the published version at https://doi.org/10.1038/s41598-021-95632-0. 


\section{Abstract \\ Purpose}

We evaluated the diagnostic accuracy of insulin-like growth factor-1 (IGF-1) for screening growth hormone deficiency (GHD) to determine the usefulness of IGF-1 as a screening test.

\section{Methods}

Among 298 consecutive children who had short stature or decreased height velocity, we measured IGF-1 levels and performed growth hormone $(\mathrm{GH})$ secretion test using clonidine, arginine, and, in cases with different results of the two tests, L-dopa. Patients with congenital abnormalities were excluded. GHD was defined as peak $\mathrm{GH} \leq 6.0 \mathrm{ng} / \mathrm{mL}$ in the two tests.

\section{Results}

We identified 60 and 238 patients with and without GHD, respectively. The mean IGF-1 (SD) was not significantly different between the GHD and non-GHD groups $(p=0.23)$. Receiver operating characteristic curve analysis demonstrated the best diagnostic accuracy at an IGF-1 cutoff of -1.493 SD, with 0.685 sensitivity, 0.417 specificity, 0.25 positive and 0.823 negative predictive values, and 0.517 area under the curve. Correlation analysis revealed that none of the items of patients' characteristics increased the diagnostic power of IGF-1.

\section{Conclusion}

IGF-1 level had poor diagnostic accuracy as a screening test for GHD. Therefore, IGF-1 should not be used alone in the screening of GHD. A predictive biomarker for GHD should be developed in the future.

\section{Introduction}

Growth hormone (GH) secretion needs to be assessed for the diagnosis of GH deficiency (GHD) by stimulation tests. However, there are several challenges associated with the $\mathrm{GH}$ secretion test [1]. Pharmacological stimuli are not physiological, and their accuracy is poor. It is well known that normally growing children may have falsely low GH responses. Moreover, the diagnostic criteria for GHD are not uniform worldwide [2]. Furthermore, the GH secretion test may be influenced by factors such obesity, undernutrition, sex, age, puberty, and presence of chronic diseases. It also has potential adverse reactions and may sometimes result in hospitalization. Therefore, a predictive biomarker for GHD is desired to avoid unnecessary $\mathrm{GH}$ secretion test. 
Insulin-like growth factor-1 (IGF-1) is a small polypeptide hormone secreted by the liver when stimulated by $\mathrm{GH}$. As serum levels of IGF-1 show little circadian variation, IGF-1 has been considered as a predictive biomarker for GHD [2]. The utility of IGF-1 for the screening of GHD was reported in some studies [3-7] but not in others $[1,8]$. As the study settings in these reports were different, it is difficult to compare the diagnostic accuracy of IGF-1. For example, the inclusion criteria for GH secretion test comprise not only short stature but also bone age [2], target height [3, 6], and catch-up growth [3]. Furthermore, the studies used different GH cutoff levels $[1,3-6,8,9]$. Therefore, a prospective cohort study was required to determine the diagnostic accuracy of IGF-1. We prospectively analyzed a cohort of children with short stature to evaluate the diagnostic accuracy of IGF-1 for the diagnosis of GHD.

\section{Materials And Methods}

\section{Patients}

This was a prospective cross-sectional study on children with short stature or decreased growth velocity who were examined at Aichi Medical University Hospital between April 2015 and March 2020. All study evaluations and procedures were performed in accordance with the Declaration of Helsinki, and Ethical Guidelines for Medical and Health Research Involving Human Subjects established by Japanese Government. We used the following inclusion criteria: (a) referred to Aichi Medical University for the evaluation of short stature or decreased growth velocity; (b) short stature of $\leq-2$ SD or height velocity of $\leq-1.5 \mathrm{SD}$ in $>2$ years below the mean for sex and age [10]; and (c) >1 year of age and before the completion of puberty, according to Tanner stages. The exclusion criteria were the presence of recognized congenital abnormalities, such as hypothyroidism; small for gestational age; Turner's syndrome; and trisomy 21.

General biochemical tests, thyroid function test, bone age, and IGF-1 were examined before GH secretion test in consecutive patients who met the inclusion criteria. The radius, ulna, and short bone method was used for evaluating bone age [11]. The patients were divided into $\mathrm{GH}$ and non-GH groups according to the response to the $\mathrm{GH}$ secretion test $(\mathrm{GH}, 60$; non- $\mathrm{GH}, 238)$. In Japan, $\mathrm{GHD}$ is diagnosed when the peak $\mathrm{GH}$ is $\leq 6.0 \mathrm{ng} / \mathrm{mL}$ in two $\mathrm{GH}$ secretion tests [9]. A cutoff of $6 \mathrm{ng} / \mathrm{mL}$ was determined by the Japanese National Health Insurance program. Stimulation tests using clonidine, arginine, and L-dopa were performed in that order, using the algorithm shown in Fig. 1. GHD was diagnosed if the $\mathrm{GH}$ peak levels were $\leq 6 \mathrm{ng} / \mathrm{mL}$ in the two stimulation tests. If the $\mathrm{GH}$ peak was above the cutoff level in the clonidine stimulation test, the next stimulation test was not performed. If the $\mathrm{GH}$ peak of the arginine stimulation test was $6-8 \mathrm{ng} / \mathrm{mL}$, the third L-dopa stimulation test was performed. If the $\mathrm{GH}$ peak of the arginine stimulation test was $>8$ $\mathrm{ng} / \mathrm{mL}$, the third test was not performed as GHD was unlikely to be present. Glucagon was not used in this study because glucagon requires a long examination time of $180 \mathrm{~min}$. Insulin was also not used in this study because of its potentially serious side effects and we were not accustomed to its use.

After overnight fasting, the stimulation test was started at 6:30 for children $<6$ years old and at 9:00 for those $>6$ years old because of fasting tolerance. Sampling was done at 0, 30, 60, 90, and 120 minutes. 
Clonidine $(5 \mu \mathrm{g} / \mathrm{kg})$, arginine (10 mg/kg), and L-dopa (10 mg/kg) were administered as the stimuli for the $\mathrm{GH}$ secretion test. Sex steroids were not used for priming before the $\mathrm{GH}$ secretion test. After the diagnosis of GHD, head MRI was performed before starting GH replacement therapy.

\section{Hormone assays}

Serum IGF-1 was measured by electrochemiluminescence immunoassay (Elecsys IGF-1; Roche Diagnostics, Tokyo, Japan), which was calibrated against the WHO International Standard 02/254. The values of serum IGF-1 were transformed into SDs, according to the established reference ranges of the assay for sex and calendar age [12]. GH was measured by immunoenzymometric assay (E Test TOSOH II HGH; Tosoh Co., Ltd., Tokyo, Japan), which was standardized against the WHO International Standard 98/574. According to the manufacture's datasheet, the intra- and interassay coefficients of variation (CV) for IGF- 1 was $<10 \%$ and $<20 \%$, and those for GH was $<10 \%$ and $<15 \%$. As GH was measured in the hospital, we tested for intra-assay CV for GH in our hospital and found that it was $2 \%$ on average. Interassay CV for GH in our hospital was not tested. IGF-1 was measured by the testing company.

\section{Statistical analysis}

We calculated point estimates for IGF-1 (SD) sensitivity, specificity, positive predictive value (PPV), negative predictive value (NPV), diagnostic efficiency (DE), positive likelihood ratio (PLR), and negative likelihood ratio (NLR) for predicting the presence of GHD. Data were shown as median (interquartile range) for chronological and bone age, and as mean \pm SD for the other numerical variables. Based on the $\mathrm{f}$-test, Student's t-test was performed in the case of homoscedasticity and the Mann-Whitney $U$ test was performed in the case of unequal variances to compare the IGF-1 level and other variables between the two groups. Spearman's rank correlation coefficient test was performed to investigate the relationship of IGF-1 (SD) with age, bone age, height (SD), target height (SD), height velocity before examination (SD), weight (SD), body mass index (BMI) (SD), and maximum peak $\mathrm{GH}(\mathrm{ng} / \mathrm{mL})$. Correlation was defined as very weak if $<0.2$, weak if $\geq 0.2$ and $<0.4$, moderate if $\geq 0.4$ and $<0.6$, strong if $\geq 0.6$ and $<0.8$, and very strong if $\geq 0.8$. Receiver operating characteristic (ROC) analysis with the Youden index was used to compare the discriminatory performances of IGF-1 in the diagnosis of GHD. Based on the area under the ROC curve (AUC), performance was considered as acceptable if $>0.7$ and $\leq 0.8$ and excellent if $>0.8$.

All statistical analyses were performed using EZR (Saitama Medical Center, Jichi Medical University, Saitama, Japan) [13], which is a graphical user interface for R (The R Foundation for Statistical Computing, Vienna, Austria). More precisely, it is a modified version of R commander designed to add statistical functions frequently used in biostatistics.

\section{Results}

The patients included in this study had a median age of 4.98 years (interquartile range, 3.21-9.38 years). We identified 60 children with GHD and 238 children without GHD (non-GHD) (Fig. 1), with male preponderance of $53.4 \%$. Four patients were diagnosed with organic GHD [lymphocytic hypophysitis $(n=$ $2)$, craniopharyngioma $(n=1)$, and cerebral myeloma $(n=1)]$. The backgrounds of these patients are 
described in Table 1. Height velocity after examination, body weight (SD), and BMI (SD) were significantly higher in the GHD group than in the non-GHD group. Maximum peak GH was significantly lower in the GHD group than in the non-GHD group.

ROC analysis showed the best diagnostic accuracy at an IGF-1 cutoff of - 1.493 SD (sensitivity, 0.417; specificity, 0.689; PPV, 0.25; NPV, 0.823; DE, 0.631; PLR, 1.322; NLR, 0.852; AUC = 0.517) (Fig. 2). Thus, using the IGF-1 (SD) cutoff of -1.493 , a correct diagnosis was possible in 26 patients with GHD and 161 subjects without GHD.

IGF-1 (SD) across the GHD and non-GHD groups showed normality in the Kolmogorov-Smirnov test but not in the Shapiro-Wilk test, and outliers were in the IGF-1 (SD) phase. Because of the possible significant impact on the number of relationships, we decided to analyze the IGF-1 (SD) using Spearman's rank correlation coefficient. The correlation of IGF-1 (SD) was weak with age $(r=-0.264, p<0.001)$, bone age $(r=-0.26, p<0.001)$, height velocity before examination (SD) $(r=0.22, p<0.001)$, weight (SD) $(r=$ $0.219, p<0.001)$, and BMI (SD) $(r=0.241, p<0.001)$ and very weak with height $(S D)(r=0.0815, p=0.16)$, target height (SD) $(r=-0.05, p=0.393)$, and maximum GH peak $(r=0.129, p=0.0257)$.

To clarify the relationship between pretreatment IGF-1 and response to GH, we compared the height velocity (SD) between groups with IGF-1 above $(n=34)$ and below $(n=26)$ the cutoff value $(-1.493$ SD). Pre- and posttreatment height velocity (SD) were similar between the groups (pretreatment, $-1.28 \pm 2.25$ vs. $-1.52 \pm 2.51, p=0.696$; posttreatment, $2.48 \pm 3.15$ vs. $2.74 \pm 3.09, p=0.755$ ).

To assess the efficacy of the third stimulation test, patients diagnosed with GHD on the second $(n=39)$ and third tests $(n=21)$ were compared (Table 2). Pre- and posttreatment growth velocities (SD) were similar between these groups (pretreatment, $-1.66 \pm 2.36$ vs. $-0.89 \pm 2.31, p=0.232$; posttreatment, 2.44 \pm 3.00 vs. $2.87 \pm 3.33, p=0.618$ ). To be more precise, the height velocity was compared according to age and sex groups (Table 2). The age was classified into two categories as those aged $\leq 9$ years and those aged $>9$ years in boys as well as those aged $\leq 8$ years and those aged $>8$ years in girls. In any subgroup, height velocity before and after the examination was not significantly different between those diagnosed on two and three tests (Table 2).

\section{Discussion}

We found that IGF-1 had poor accuracy as demonstrated by low AUC, and poor sensitivity, specificity, and $\mathrm{DE}$ for the best cutoff of $-1.493 \mathrm{SD}$. The correlation analysis revealed that none of the items increased the diagnostic power of IGF-1 for GHD screening.

IGF-1 has been reported to be useful in the screening of GHD in some studies [3-7] but not in others [1, 8]. The reason for these contradictory results is that the patient groups and GHD cutoff values differed between these studies. First, the inclusion criteria may create differences in patient backgrounds. In previous studies on the usefulness of IGF-1 for GHD screening, patients were selected according to bone age [2], target height [3, 6], or catch-up growth [3] in addition to short stature and/or height velocity. These 
variations in inclusion criteria might superficially improve the sensitivity and specificity of IGF-1. Second, different GH cutoff levels for GHD were selected: $\leq 5 \mathrm{ng} / \mathrm{mL}[5,6], \leq 6 \mathrm{ng} / \mathrm{mL}[9], \leq 7 \mathrm{ng} / \mathrm{mL}$ [1], $\leq 8$ $\mathrm{ng} / \mathrm{mL}[3,8]$, and $\leq 10 \mathrm{ng} / \mathrm{mL}[4]$. In the case of $\leq 8$ or $\leq 10 \mathrm{ng} / \mathrm{mL}[3,8]$, the prevalence of GHD in patients with short stature was $>30 \%$, which was higher than that in our study $(20.1 \%)$. Since disease prevalence affects sensitivity, specificity, PPV, and NPV, IGF-1 is not a useful screening test in a patient population with low prevalence of GHD. In the cohort of this study, the prevalence of GHD was decreased to $12.8 \%$ when the $\mathrm{GH}$ cutoff level of $5 \mathrm{ng} / \mathrm{mL}$ was selected. Therefore, when evaluating the efficacy of IGF-1, comparisons should be made at the same GH cutoff levels.

Bone age, target height, and height velocity should be taken into consideration before selecting patients for the $\mathrm{GH}$ secretion test [2]. In our study, bone age, target height, and height velocity before the examination were similar between the GHD and non-GHD groups. Even after combining these conditions with IGF-1, the diagnostic power of IGF-1 for GHD screening did not increase. Therefore, it would be difficult to distinguish patients with GHD from those without GHD using those parameters.

To clarify the relationship between pretreatment IGF-1 and response to $\mathrm{GH}$, height velocity (SD) between groups with IGF-1 above $(n=34)$ and below $(n=26)$ the cutoff value $(-1.493$ SD) was compared. Preand posttreatment height velocity (SD) were similar between the groups. IGF-1 was reported to be weakly correlated with the clinical endpoints of GH treatment [14]. Therefore, it would be difficult to predict the degree of improvement prior to GH treatment using pretreatment IGF-1.

We performed the third stimulation test when the results of $\mathrm{GH}$ secretion in the first and second tests were different. Although a sufficient GH response in one stimulation test rules out GHD in most cases [2], the utilization and interpretation of the drugs used in the stimulation test depends on the facility $[1,15]$. In this study, pre- and posttreatment growth velocities were similar between the patients diagnosed with GHD on the second and third tests (Table 2). In any subgroup, height velocity before and after examination was not significantly different between those diagnosed on two and three tests. This result indicated that patients diagnosed with GHD by the third test have the similar response to growth hormone as those diagnosed by the traditional method. Therefore, the third simulation test may have some significance in diagnosing patients with GHD.

This study had several limitations. First, immunoassay for IGF-1 analysis is not the most sensitive assay. The variations in immunoassays used in different studies may result in variations in the reported efficacy of IGF-1. More accurate assays, such as LC-MS, may reveal the actual usefulness of IGF-1 for GHD screening. Second, the use of a third stimulation test is not a common practice. If one of the tests is normal, there is no need for a third one. Thus, if the cutoff for a normal GH peak is set at $6 \mathrm{ng} / \mathrm{ml}$, all responses above 6 should be considered normal. However, depending on the order of each stimulation test, the diagnosis of GHD may vary among patients. For example, a patient with a peak $\mathrm{GH}<6 \mathrm{ng} / \mathrm{mL}$ in $A$ and $B$ stimulation tests and $\geq 6 \mathrm{ng} / \mathrm{mL}$ in C stimulation test would not be diagnosed with $G H D$ if the order of the stimulation tests were $\mathrm{A}, \mathrm{C}$, and $\mathrm{B}$. There is no evidence on the order of stimulation tests, and the order varies from institution to institution. In the present study, the response to $\mathrm{GH}$ was similar in 
patients who had substandard results in two of the two stimulation tests and in those who had substandard results in two of the three stimulation tests. Therefore, it is necessary to accumulate such cases to clarify the significance of the third stimulation test.

In conclusion, IGF-1 level had poor diagnostic accuracy as a screening test for GHD. Correlation analysis revealed that none of the items increased the diagnostic power of IGF-1. Therefore, IGF-1 should not be used alone for the screening of GHD. A predictive biomarker for GHD should be developed in the future.

\section{Declarations}

\section{Acknowledgments}

We acknowledge assistance from ENAGO for English language editing.

\section{Author contributions}

$\mathrm{HI}$ contributed to study design and data interpretation and was a major contributor in manuscript writing. SK, JS, RM, TH, YK, TM, and HK contributed to data acquisition and analysis. WO, JT, and AO critically revised the manuscript for important intellectual content. HI contributed to the final approval of the version to be published. All authors read and approved the final manuscript.

\section{Additional information}

Funding: The authors declare that they received no funding for this research.

\section{Conflicts of interest}

The authors declare no competing interests.

\section{Availability of data and material}

The data that support the findings of this study are available upon request from the corresponding author. The data are not publicly available because of privacy and ethical restrictions.

\section{Ethics approval}

The study was approved by the ethics committee of Aichi Medical University (originally 2015-H359 but revised to $2020-\mathrm{H} 041$ as the study period was updated).

\section{Consent to participate and for publication}

The parents of the study subjects provided consent to participate and for publication after full explanation of the purpose and nature of all the procedures used in this study.

\section{References}


1. Ibba, A. et al. IGF1 for the diagnosis of growth hormone deficiency in children and adolescents: a reappraisal. Endocr. Connect.9, 1095-1102 (2020).

2. Collett-Solberg, P. F. et al. Growth hormone therapy in children; research and practice - a review. Growth Horm. IGF Res.44, 20-32 (2019).

3. Binder, G., Huller, E., Blumenstock, G. \& Schweizer, R. Auxology-based cut-off values for biochemical testing of GH secretion in childhood. Growth Horm. IGF Res.21, 212-218 (2011).

4. Guzzetti, C. et al. Cut-off limits of the peak GH response to stimulation tests for the diagnosis of GH deficiency in children and adolescents: study in patients with organic GHD. Eur. J. Endocrinol.175, 41-47 (2016).

5. Inoue-Lima, T. H. et al. IGF-1 assessed by pubertal status has the best positive predictive power for GH deficiency diagnosis in peripubertal children. J. Pediatr. Endocrinol. Metab.32, 173-179 (2019).

6. Inoue-Lima, T. H. et al. A bayesian approach to diagnose growth hormone deficiency in children: insulin-like growth factor type 1 is valuable for screening and IGF-binding protein type 3 for confirmation. Horm. Res. Paediatr.93, 197-205 (2020).

7. Shen, Y. et al. Diagnostic value of serum IGF-1 and IGFBP-3 in growth hormone deficiency: a systematic review with meta-analysis. Eur. J. Pediatr.174, 419-427 (2015).

8. Galluzzi, F. et al. Are IGF-I and IGF-BP3 useful for diagnosing growth hormone deficiency in children of short stature? J. Pediatr. Endocrinol. Metab.23, 1273-1279 (2010).

9. Katsumata, N. et al. Continuing efforts to standardize measured serum growth hormone values in Japan. Endocr. J.63, 933-936 (2016).

10. Isojima, T., Kato, N., Ito, Y., Kanzaki, S. \& Murata, M. Growth standard charts for Japanese children with mean and standard deviation (SD) values based on the year 2000 national survey. Clin. Pediatr. Endocrinol.25, 71-76 (2016).

11. Murata, M. Japanese specific bone age standard on the TW2. Clin. Pediatr. Endocrinol.2, 35-41 (1993).

12. Isojima, T. et al. Standardized centile curves and reference intervals of serum insulin-like growth factor-I (IGF-I) levels in a normal Japanese population using the LMS method. Endocr. J.59, 771-780 (2012).

13. Kanda, Y. Investigation of the freely available easy-to-use software 'EZR' for medical statistics. Bone Marrow Transplant.48, 452-458 (2013).

14. Johannsson, G. et al. Growth Hormone Research Society perspective on biomarkers of GH action in children and adults. Endocr. Connect.7, R126-R134 (2018).

15. Chesover, A. D. \& Dattani, M. T. Evaluation of growth hormone stimulation testing in children. Clin. Endocrinol. (Oxf) 84, 708-714 (2016).

\section{Tables}

Table 1. Background characteristics of the GHD and non-GHD groups 


\begin{tabular}{llll}
\hline & GHD group $(\mathrm{n}=60)$ & Non-GHD group $(\mathrm{n}=238)$ & $\mathrm{p}$ value \\
\hline Male:female & 34.26 & $125: 113$ & 0.664 \\
Age (year) & $5.10(3.37-10.03)$ & $4.94(3.19-9.17)$ & 0.565 \\
Bone age (year) & $3.21(2.42-7.90)$ & $3.21(2.42-7.5)$ & 0.778 \\
Prepubertal:pubertal & $58: 2$ & $224: 14$ & 0.748 \\
Height (SD) & $-2.32 \pm 0.76$ & $-2.37 \pm 0.82$ & 0.645 \\
Target height (SD) & $-0.49 \pm 0.69$ & $0.47 \pm 0.71$ & 0.869 \\
Height velocity before examination (SD) & $-1.39 \pm 2.35$ & $-0.97 \pm 1.93$ & 0.157 \\
Height velocity after examination (SD) & $2.60 \pm 3.10$ & $-0.12 \pm 2.96$ & $<0.001$ \\
Weight (SD) & $-1.61 \pm 0.96$ & $-2.00 \pm 1.08$ & 0.0144 \\
BMI (SD) & $-0.11 \pm 1.11$ & $-0.50 \pm 1.12$ & 0.0207 \\
Max. Peak GH (ng/mL) & $5.94 \pm 2.63$ & $11.17 \pm 3.97$ & $<0.001$ \\
IGF-1 (SD) & $-1.43 \pm 1.14$ & $-1.12 \pm 0.88$ & 0.23 \\
\hline
\end{tabular}

The values were expressed as median (IQR) or mean $\pm \mathrm{SD}$

BMI, body mass index; GH, growth hormone; GHD, growth hormone deficiency; IGF-1, insulin-like growth factor; IQR, interquartile range;

Max., maximum

Table 2. The analysis about height velocity (HV) before and after examination according to age groups. 


\begin{tabular}{|c|c|c|c|c|c|c|}
\hline & \multicolumn{3}{|c|}{ HV before examination } & \multicolumn{3}{|c|}{$\begin{array}{l}\text { HV after } \\
\text { examination }\end{array}$} \\
\hline & 2 tests & 3 tests & $\begin{array}{l}\mathrm{p} \\
\text { value }\end{array}$ & 2 tests & 3 tests & $\begin{array}{l}\mathrm{p} \\
\text { value }\end{array}$ \\
\hline all patient with GHD & $\begin{array}{l}-1.66 \pm 2.36(n \\
=39)\end{array}$ & $\begin{array}{l}-0.89 \pm 2.31(\mathrm{n} \\
=21)\end{array}$ & 0.232 & $\begin{array}{l}2.44 \pm \\
3.00\end{array}$ & $\begin{array}{l}2.87 \pm \\
3.33\end{array}$ & 0.618 \\
\hline Male with GHD & $\begin{array}{l}-1.69 \pm 2.57(\mathrm{n} \\
=22)\end{array}$ & $\begin{array}{l}-1.03 \pm 2.72(\mathrm{n} \\
=12)\end{array}$ & 0.49 & $\begin{array}{l}2.18 \pm \\
3.31\end{array}$ & $\begin{array}{l}2.94 \pm \\
3.02\end{array}$ & 0.523 \\
\hline $\begin{array}{l}\text { Male with GHD, } \leq 9 \\
\text { years old }\end{array}$ & $\begin{array}{l}-1.47 \pm 2.11(\mathrm{n} \\
=12)\end{array}$ & $\begin{array}{l}-1.26 \pm 2.68(\mathrm{n} \\
=9)\end{array}$ & 0.845 & $\begin{array}{l}2.44 \pm \\
2.76\end{array}$ & $\begin{array}{l}2.58 \pm \\
3.24\end{array}$ & 0.914 \\
\hline $\begin{array}{l}\text { Male with GHD, >9 } \\
\text { years old }\end{array}$ & $\begin{array}{l}-1.96 \pm 3.14(\mathrm{n} \\
=10)\end{array}$ & $\begin{array}{l}-0.35 \pm 3.33(n \\
=3)\end{array}$ & 0.458 & $\begin{array}{l}1.88 \pm \\
4.03\end{array}$ & $\begin{array}{l}4.01 \pm \\
2.44\end{array}$ & 0.414 \\
\hline Female with GHD & $\begin{array}{l}-1.61 \pm 2.12(\mathrm{n} \\
=17)\end{array}$ & $\begin{array}{l}-0.70 \pm 1.75(\mathrm{n} \\
=9)\end{array}$ & 0.281 & $\begin{array}{l}2.75 \pm \\
2.63\end{array}$ & $\begin{array}{l}2.77 \pm \\
3.89\end{array}$ & 0.99 \\
\hline $\begin{array}{l}\text { Female with } \mathrm{GHD}, \leq 8 \\
\text { years old }\end{array}$ & $\begin{array}{l}-1.38 \pm 2.16(\mathrm{n} \\
=13)\end{array}$ & $\begin{array}{l}-1.01 \pm 1.62(\mathrm{n} \\
=7)\end{array}$ & 0.698 & $\begin{array}{l}3.16 \pm \\
2.75\end{array}$ & $\begin{array}{l}2.04 \pm \\
1.64\end{array}$ & 0.343 \\
\hline $\begin{array}{l}\text { Female with } \mathrm{GHD},>8 \\
\text { years old }\end{array}$ & $\begin{array}{l}-2.34 \pm 2.10(n \\
=4)\end{array}$ & $\begin{array}{l}0.40 \pm 2.35(\mathrm{n} \\
=2)\end{array}$ & 0.216 & $\begin{array}{l}1.54 \pm \\
2.06\end{array}$ & $\begin{array}{l}5.33 \pm \\
9.38\end{array}$ & 0.431 \\
\hline
\end{tabular}

Figures 


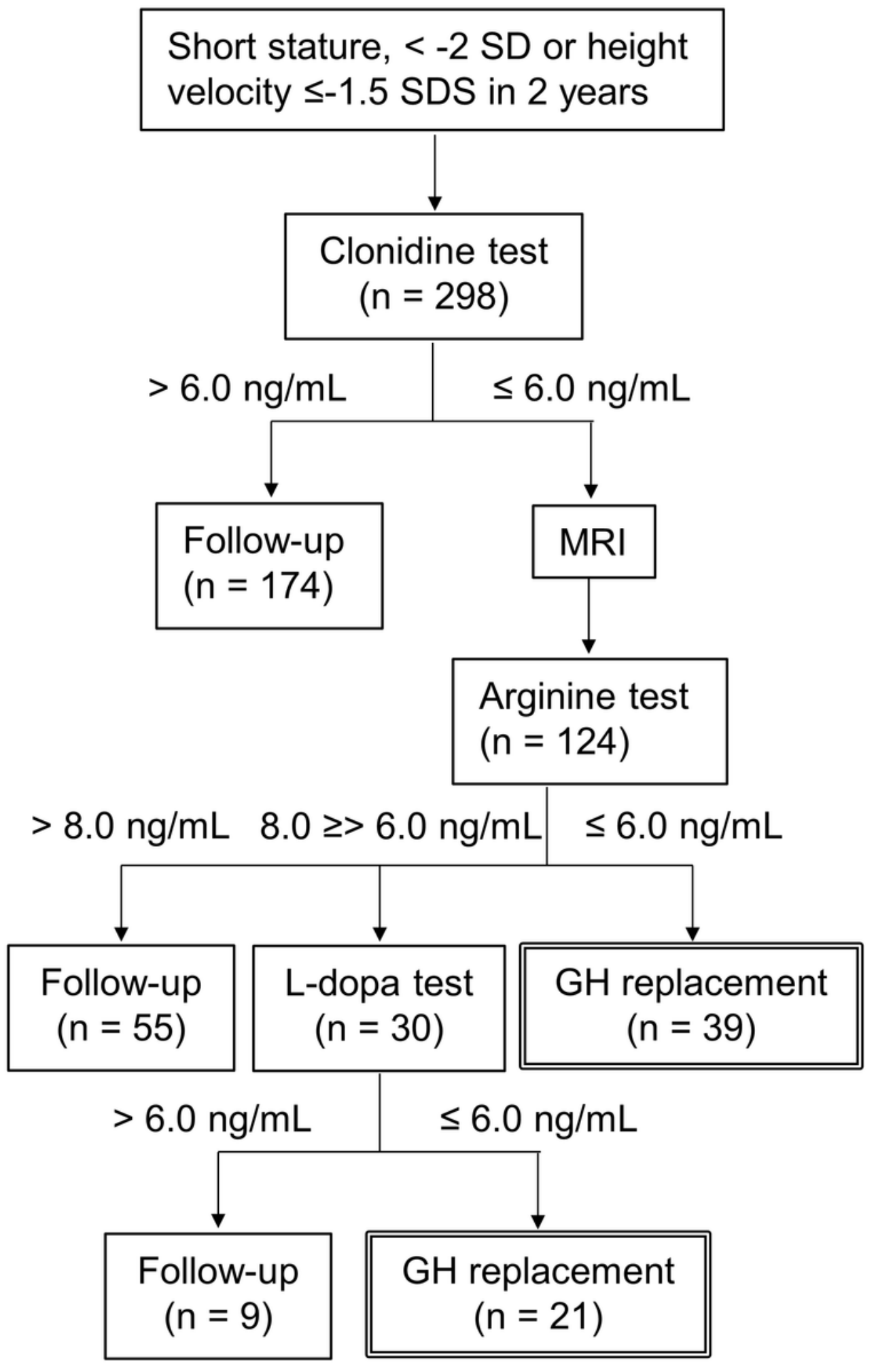

Figure 1

Algorithm of the stimulation tests using clonidine, arginine, and L-dopa If peak growth hormone (GH) in both clonidine and arginine tests was $\leq 6.0 \mathrm{ng} / \mathrm{mL}, \mathrm{GH}$ replacement therapy was initiated. When the peak $\mathrm{GH}$ in arginine test was $6.0-8.0 \mathrm{ng} / \mathrm{mL}$, the third stimulation test using L-dopa was performed. 


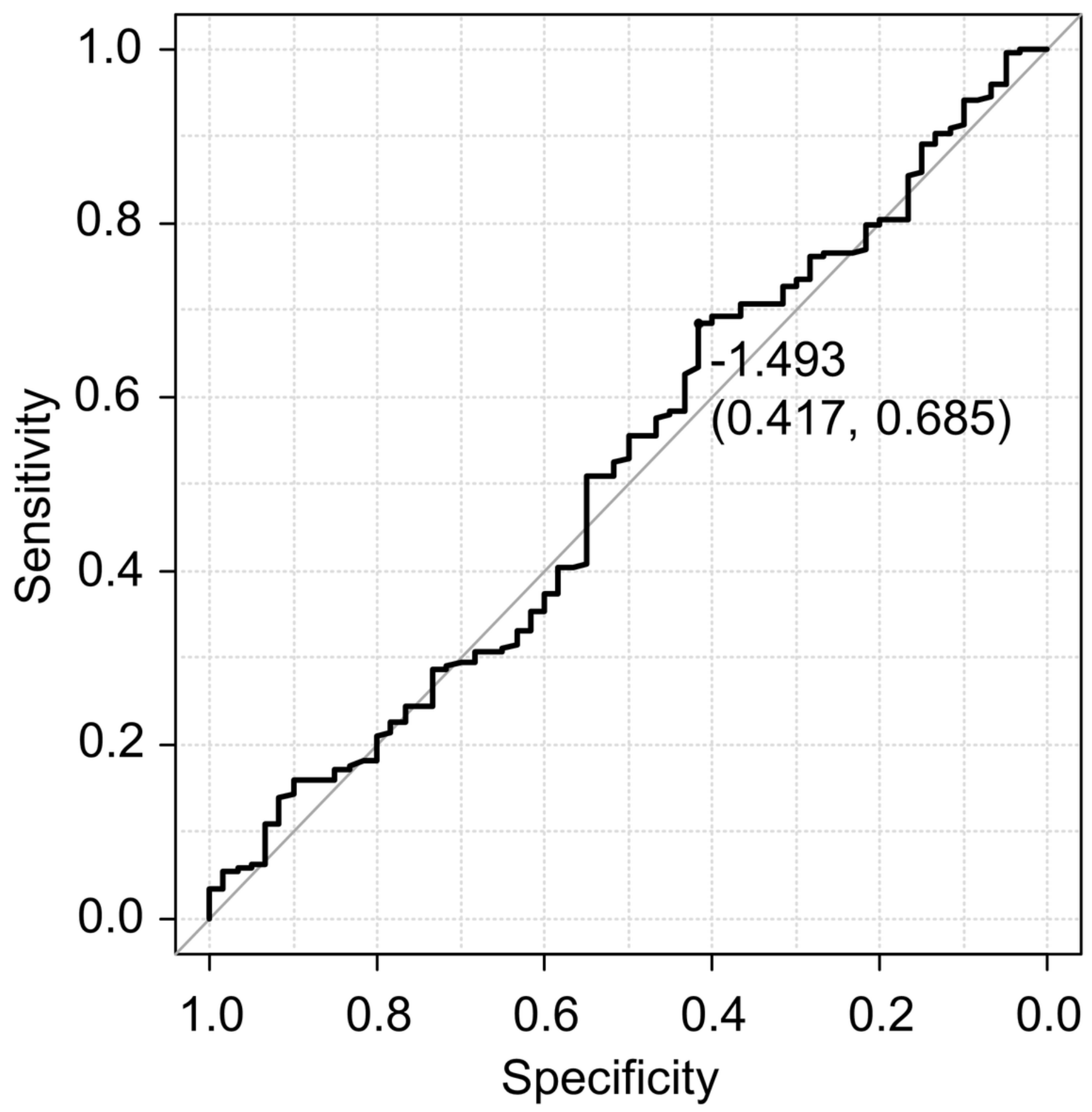

Figure 2

Receiver operating characteristic (ROC) curve of IGF-1 (SD) for the diagnosis of growth hormone deficiency (GHD) ROC analysis showed the best diagnostic accuracy at an IGF-1 cutoff of $-1.493 \mathrm{SD}$ (sensitivity, 0.685; specificity, 0.417; area under the ROC curve, 0.517). 